\title{
A density model for mantle carbonate- rich melts and applications to carbonatite magmatism in the upper mantle
}

\author{
MALCOLM MASSUYEAU ${ }^{1}$, XENIA RITTER ${ }^{1,2}$ AND \\ CARMEN SANCHEZ-VALLE ${ }^{3}$ \\ ${ }^{1}$ University of Münster \\ ${ }^{2}$ University of Chicago \\ ${ }^{3}$ Universität Münster \\ Presenting Author: malcolm.massuyeau@wwu.de
}

Volatiles cycle plays a leading role in the evolution and fate of a planet, defining habitability conditions at the surface as well as the physicochemical properties of the inner layers. Conversely, chemical and physical interactions between the inner and outer layers shape the evolution of the volatiles cycle. On Earth, the mantle constitutes a major actor of the volatiles cycle by hosting considerable amounts of carbon and hydrogen. Pressuretemperature-composition conditions prevailing within the Earth's upper mantle allow for stabilizing $\mathrm{CO}_{2}$-rich (carbonatite) melts that are important conveyors for the distribution of volatiles $\mathrm{CO}_{2}$ $\mathrm{H}_{2} \mathrm{O}$. Their efficiency in transporting such volatiles resides in their mobility properties. Yet, modelling their mobility is still critically prevented by the lack of fundamental constraints on their density (and viscosity). Taking advantage of new high pressure-high temperature data recently acquired by both experimental and computational methods, we propose here a model for the density of mantle-derived carbonate-rich melts in the system $\mathrm{MgO}-\mathrm{CaO}-\mathrm{Na}_{2} \mathrm{O}-\mathrm{K}_{2} \mathrm{O}-\mathrm{Li}_{2} \mathrm{O}-\mathrm{H}_{2} \mathrm{O}-\mathrm{CO}_{2}$.

Calibrated over a comprehensive database comprising $>880$ density data points, our model is conceived to be continuous in pressure-, temperature- and composition-space, and allows for predictions of the carbonate melt density up to $15 \mathrm{GPa}$ and 2000 ${ }^{\circ} \mathrm{C}$. It reasonably assumes a linear dependence on composition of the multicomponent carbonate melt volumes, and employs a simple Murnaghan equation of state in order to calculate the volumetric properties of multicomponent carbonate melts in the system $\mathrm{MgO}-\mathrm{CaO}-\mathrm{Na}_{2} \mathrm{O}-\mathrm{K}_{2} \mathrm{O}-\mathrm{Li}_{2} \mathrm{O}-\mathrm{H}_{2} \mathrm{O}-\mathrm{CO}_{2}$. Combined with reasonable assumptions on volumetric properties for $\mathrm{SiO}_{2}$ and $\mathrm{FeO}$, we simulate the density and seismic P-wave velocity $\mathrm{V}_{\mathrm{P}}$ of carbonate-rich melts experimentally equilibrated with various mantle lithologies (e.g., peridotite, eclogite, pelite), and discuss about implications. 